\title{
Methicillin resistant Staphylococcus aureus: prevalence and antibiogram in a tertiary care hospital in western Nepal
}

\author{
Hare Krishna Tiwari, Ayan Kumar Das, Darshan Sapkota, Kunjukunju Sivarajan, Vijay Kumar \\ Pahwa
}

Department of Microbiology, Universal College of Medical Sciences, Bhairahawa, Lumbini Zone, Nepal

\begin{abstract}
Background: Methicillin resistant Staphylococcus aureus (MRSA) is a major cause of nosocomial and community infections. Its prevalence varies with country and with hospitals within a country. The current study estimates the prevalence of MRSA strains and investigates their antibiogram in western Nepal.

Methodology: A total of 162 S. aureus strains were isolated from various clinical specimens, and antibiotic susceptibility tests were performed using disc diffusion, growth on oxacillin screen agar, and oxacillin minimum inhibitory concentration (MIC).

Results: One hundred and twelve $(69.1 \%)$ strains were found to be MRSA, of which $37(33.1 \%)$ were community acquired and 75 (66.9\%) were hospital acquired. Of 112 MRSA strains, 45 (40.1\%) were multi-drug resistant. All MRSA strains were found resistant to penicillin, and $91.9 \%, 87.4 \%, 77 \%$, and $55.5 \%$ were resistant to amoxicillin, ampicillin, trimethoprim/sulfamethoxazole, and cephalexin, respectively. However, low resistance was observed with amikacin (19\%), ciprofloxacin (26.5\%), and norfloxacin (30.6\%). All strains were sensitive to vancomycin.

Conclusion: The reported rate of MRSA prevalence is alarming. Given the ability of MRSA to spread from person to person, it is necessary to adhere to rational use of antibiotics and to raise awareness among the concerned communities and tourists who visit this area.
\end{abstract}

Key words: MRSA, western region, prevalence, Nepal

J Infect Dev Ctries 2009; 3(9):681-684.

Received May 25, 2009 - Accepted August 29, 2009

Copyright (c) 2009 Tiwari et al. This is an open-access article distributed under the Creative Commons Attribution License, which permits unrestricted use, distribution, and reproduction in any medium, provided the original work is properly cited.

\section{Introduction}

Staphylococcus aureus causes a variety of infections, ranging from minor skin diseases to lifethreatening endocarditis [1]. It has evolved to overcome most therapeutic agents. MRSA strains are widespread in hospitals and communities [2] and the emergence of multi-drug resistant MRSA has posed a serious therapeutic challenge, leaving glycopeptides as the drugs of choice. Prolonged hospital stay and indiscriminate use of antibiotics increase the chance of emergence and spread of MRSA [3].

In interior and remote regions of Nepal where availability and use of antibiotics is limited, the prevalence of MRSA is low [4]. On the other hand, no study addressing MRSA prevalence has been conducted in the western region, which has relatively better health care facilities, offers easier access to antibiotics, and receives many patients from neighboring states of India. Therefore, the present study estimates the percentage of MRSA strains and investigates their antibiotic resistance profiles in this region of Nepal. Moreover, since this region receives a significant number of tourists throughout the year, this study is more important given the capacity of MRSA to spread.

\section{Materials and methods}

During June 2005 and July 2007, a total of 162 strains of $S$. aureus were isolated from various clinical specimens from different patients visiting and admitted to the Universal College of Medical Sciences Teaching Hospital, Bhairahawa, a 700-bed tertiary care hospital in western Nepal.

Specimens were inoculated onto blood agar and MacConkey agar (Hi-Media, India). Urine specimens were inoculated onto cysteine lactose electrolyte deficient agar (Hi-Media, India). S. aureus strains were identified based on standard tests [5]. S. aureus ATCC 25923 (mecA negative) and ATCC 43300 (mecA positive) were used for the quality control of all the tests. 


\section{Disc diffusion test by Kirby-Bauer method}

Mueller-Hinton agar (MHA) plates were overlaid with the saline suspension of a strain (turbidity $=0.5$ McFarland standard) and antibiotic discs of penicillin

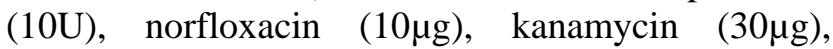
erythromycin $(15 \mu \mathrm{g})$, oxacillin $(1 \mu \mathrm{g})$, ampicillin $(10$ $\mu \mathrm{g})$, amoxicillin $(20 \mu \mathrm{g})$, tetracycline $(30 \mu \mathrm{g})$, trimethoprim/sulfamethoxazole $\quad(1.25 \mu \mathrm{g} / 23.75 \mu \mathrm{g})$, ciprofloxacin $(5 \mu \mathrm{g})$, cephalexin $(30 \mu \mathrm{g})$, amikacin $(30 \mu \mathrm{g})$, vancomycin $(30 \mu \mathrm{g})$, and cefazolin $(30 \mu \mathrm{g})$ (Hi-Media, India). After 24 and 48 hours of incubation at $35^{\circ} \mathrm{C}$, all plates were read according to standard procedure [6].

\section{Oxacillin MIC}

Gradient plates of MHA containing $2 \% \mathrm{NaCl}$ were prepared with doubling dilutions (from 0.25 $\mathrm{mg} / \mathrm{l}$ to $256 \mathrm{mg} / \mathrm{l})$ of oxacillin. Inoculum was prepared by diluting 0.5 McFarland equivalent suspension of a strain with sterile normal saline to the concentration of $10^{4} \mathrm{CFU} / \mathrm{ml}$. The plates were spotinoculated and incubated at $35^{\circ} \mathrm{C}$ for 24 hours. An oxacillin $\mathrm{MIC}$ of $\leq 2 \mathrm{mg} / 1$ indicated that the strain was susceptible, and MIC > $2 \mathrm{mg} / \mathrm{l}$ indicated that the strain was resistant [7].

\section{Oxacillin screen agar test}

The saline suspension of a strain (turbidity $=0.5$ McFarland tube) was spotted on the MHA plate containing $6 \mu \mathrm{g} / \mathrm{ml}$ oxacillin and $4 \% \mathrm{NaCl}$. Any visible growth after 24 or 48 hours of incubation at $35^{\circ} \mathrm{C}$ was indicative of resistance [7].

\section{Results}

Out of 162 isolates, $112(69.1 \%)$ were found to be methicillin resistant. Table 1 shows the distribution of S. aureus, MRSA, and multi-drug resistant MRSA in various clinical specimens. Seventy-one percent of MRSA isolates were from pus swabs or aspirates. Of the total number of MRSA, 37 (33.1\%) were from community acquired infections and 75 (66.9\%) were from nosocomial infections (table 2).

Of the 112 MRSA isolates, 45 (41\%) were multidrug resistant, of which most $(22 \%)$ were from urine samples. Table 3 shows the antibiotic profile of all the MRSA strains. Very high degrees of resistance were observed with penicillin (100\%), amoxicillin (91.8\%), ampicillin (90\%), cotrimoxazole (72.7\%), and cephalexin $(66.03 \%)$; relatively lower degrees of resistance were observed with amikacin (40\%),
Table 1. Source of staphylococcal isolates in various clinical samples.

\begin{tabular}{|c|c|c|c|}
\hline Clinical sample & $\begin{array}{c}\text { S. aureus } \\
\text { (Total } \\
162)\end{array}$ & $\begin{array}{c}\text { MRSA } \\
\text { (Total } \\
112)\end{array}$ & $\begin{array}{c}\text { MDR- } \\
\text { MRSA } \\
\text { (Total }= \\
45)\end{array}$ \\
\hline Blood & $10.5 \%$ & $6.1 \%$ & $4.6 \%$ \\
\hline $\begin{array}{c}\text { Pus } \\
\text { swab/aspirate }\end{array}$ & $63.7 \%$ & $71.2 \%$ & $66.6 \%$ \\
\hline $\begin{array}{c}\text { Pleural/synovial } \\
\text { fluid }\end{array}$ & $4 \%$ & $2.4 \%$ & $0.0 \%$ \\
\hline $\begin{array}{c}\text { Sputum/ throat } \\
\text { swab }\end{array}$ & $6 \%$ & $6.1 \%$ & $6.6 \%$ \\
\hline Urine & $14 \%$ & $13.2 \%$ & $22.2 \%$ \\
\hline CSF & $1.8 \%$ & $0.8 \%$ & $0 \%$ \\
\hline
\end{tabular}

ciprofloxacin (45.8\%), and norfloxacin

$(43.4 \%)$

(table 3).

\section{Discussion}

It is worrisome that the present study reports the MRSA prevalence rate of $69.1 \%$. We are reporting such a high prevalence for the first time in Nepal. There are three published studies on MRSA prevalence from different regions of this country. The earliest study reports a prevalence of $29 \%$ in 1990 when there were fewer heath care institutions and less access to antibiotics [8]. The second study reports a prevalence of $15.4 \%$ from remote western Nepal, where antibiotics are not easily available [4]. Finally, the third study reports MRSA prevalence of $26.14 \%$ and the authors attribute this low rate to effective infection control practice in their hospital [9].

The MRSA prevalence rates vary in various countries, with some reporting rates higher than ours [10,11,12,13,14]. During 1999 and 2002, the rates have significantly soared in various European countries such as Belgium (from 22\% to 27\%), Ireland (39\%-45\%), Germany (9\%-19\%), the Netherlands $(0.4 \%-1 \%)$ and the United Kingdom $(31 \%-45 \%)$ [15]. A report examining S. aureus isolates from the continental United States during 2004 and 2005 revealed 52\% MRSA, with the statewise prevalence ranging from $12.5 \%$ to as high as $100 \%$ [16].

Our findings of $66.9 \%$ MRSA from inpatients and $33.1 \%$ from outpatient departments are consistent with those of a national study that reports $70 \%$ and $30 \%$ prevalence in the two settings, respectively [9]. Most (71.4\%) MRSA strains were from pus, similar to the findings of a study form Pakistan [12]. 
Table 2. Distribution of community acquired and hospital acquired MRSA in various clinical specimens.

\begin{tabular}{|c|c|c|}
\hline Specimen & $\begin{array}{c}\text { CA-MRSA } \\
(\mathrm{n}=37)\end{array}$ & $\begin{array}{c}\text { HA-MRSA } \\
(\mathrm{n}=75)\end{array}$ \\
\hline Pus swab/aspirate & 24 & 57 \\
\hline Blood & - & 04 \\
\hline Urine & 10 & 05 \\
\hline CSF & - & 3 \\
\hline Sputum/throat swab & 3 & 3 \\
\hline Pleural fluid & - & 3 \\
\hline
\end{tabular}

Note: $\mathrm{CA}=$ community acquired; $\mathrm{HA}=$ hospital acquired

Table 3. Antibiotic resistance profile of $S$. aureus, MRSA, and multi-drug resistant MRSA

\begin{tabular}{|c|c|c|c|}
\hline \multirow[t]{2}{*}{ ANTIBIOTIC } & \multicolumn{3}{|c|}{ RESISTANCE percentage } \\
\hline & $\begin{array}{c}\text { S. aureus } \\
\mathrm{n}=162\end{array}$ & $\begin{array}{l}\mathrm{MRSA} \\
\mathrm{n}=112\end{array}$ & $\begin{array}{c}\text { Multi drug resistant } \\
\text { MRSA } n=45\end{array}$ \\
\hline Penicillin & 81.5 & 100 & 100 \\
\hline Norfloxacin & 30.6 & 43.4 & 58.9 \\
\hline Kanamycin & 40 & 56.5 & 64.8 \\
\hline Erythromycin & 71.7 & 68.7 & 53.4 \\
\hline Cloxacillin & 69.1 & 100 & 100 \\
\hline Ampicillin & 87.4 & 90 & 100 \\
\hline Amoxicillin & 91.9 & 91.8 & 95.5 \\
\hline Tetracycline & 39.6 & 52.3 & 64.3 \\
\hline Trimethoprim/Sulfamethoxazole & 77 & 72.7 & 82.4 \\
\hline Ciprofloxacin & 26.5 & 45.8 & 61.2 \\
\hline Cephalexin & 55.5 & 66.03 & 80.5 \\
\hline Amikacin & 19.0 & 40 & 50.0 \\
\hline Cefazolin & 54.5 & 57.6 & 82.8 \\
\hline Vancomycin & 00 & 00 & 00 \\
\hline
\end{tabular}

Equally worrisome is the extent of resistance shown by MRSA strains to other antibiotics. We found $41 \%$ of MRSA strains resistant to three or more antibiotics at a given point of time and defined such strains as multi-drug resistant. In Nepal, 78\% and $>65 \%$ of multi drug resistant MRSA strains have been reported in two different regions [4,9], whereas in the neighboring country India, the burden of such strains has ranged from $23.2 \%$, to $32 \%$, to $63.6 \%$ $[17,18,19]$. One possible consequence of reporting high rates of multi-drug resistant MRSA is exploitation of vancomycin by clinicians. However, the current study reports that antibiotics other than vancomycin-for instance, amikacin, norfloxacin, ciprofloxacin - can be promising if susceptibility testing is done, reserving vancomycin for lifethreatening infections caused by multi-drug resistant MRSA. Although none of the isolates showed vancomycin resistance in the current study, the fear of its emergence should still restrict its injudicious use.
The pattern of antibiotic susceptibility of MSSA and MRSA isolates differed significantly. The MSSA isolates were susceptible to most of the antibiotics tested, although resistance of some extent was observed with penicillin, ampicillin, and amoxicillin, and to some extent to trimethoprim/sulfamethoxazole, the antibiotics often used to treat general infections. In contrast, in the case of MRSA, multiple drug resistance was common and only a few antibiotics were active against these isolates; amikacin, erythromycin and norfloxacin were the antibiotics to which the resistance was least. The antibiotic sensitivity patterns of community acquired MRSA and hospital acquired MRSA did not differ significantly (table 2). This observation could be due to the lack of clear-cut demarcation between community and hospital isolates in our study.

Antibiotics can be bought without prescription, and some practitioners and pharmacists frequently prescribe/sell unnecessary antibiotics for their petty gain [20]. Next, poor quality antibiotics are produced at local levels, and patients show poor compliance to 
costly antimicrobials [21]. Moreover, antibiotics are prescribed without doing drug sensitivity testing due to lack of laboratory facilities in most of the health care centers of this region. Even where the facility is available, medical practitioners do not routinely recommend the test because of negligence or patients' poor economic status. All these factors might have contributed to the data showing very high prevalence reported by this study (table 3 ). The increased number of health care institutions and easier access to antibiotics in this region and lack of an effective infection control policy in our hospital might also have played a role.

A recent study has revealed the $100 \%$ activity of daptomycin against multi-drug resistant $S$. aureus isolates and it would be an excellent drug of choice to treat infections caused by such resistant strains [22].

The most effective way to prevent therapeutic crisis due to MRSA infections is to do continuous surveillance on the antibiotic resistance profiles of local $S$. aureus isolates to formulate antibiotic policies and an effective infection control program.

\section{Acknowledgement}

The authors are thankful to their laboratory staff for supporting this work.

\section{References}

1. Chambers HF (2001) The changing epidemiology of Staphylococcus aureus? Emerg Infect Dis 7: 178-182.

2. National Nosocomial Infections Surveillance System (1999) National Nosocomial Infections Surveillance System report, data summary from January 1990-May 1999, issued June 1999. Am J Infect Control 27: 520-532.

3. Levy SB (1982) Microbial resistance to antibiotics. Lancet 2: 83-88.

4. Subedi S and Brahmadathan K N (2005) Antimicrobial susceptibility patterns of clinical isolates of Staphylococcus aureus in Nepal. Eur Soci Clin Microbiol Infect Dis 11: 3537.

5. Baird D (1996) Staphylococcus: cluster-forming Gram positive cocci. In: Collee JG, Marmion BP, Fraser AG, Simmons A, eds. Mackie and McCartney practical medical microbiology. London: Churchill Livingstone; 245-250.

6. National Committee for Clinical Laboratory Standards (2004) Performance Standards for antimicrobial Disc Susceptibility Testing: Fourteenth Informational Supplement M100-S14. NCCLS, Wayne, PA, USA.

7. National Committee for Clinical Laboratory Standards (2003) Methods for Dilution Antimicrobial Susceptibility Tests for Bacteria that Grow Aerobically: Approved Standard M7-A6. NCCLS, Wayne, PA, USA.

8. Rai SK, Talukdar NR and Shrestha HG (1990) Methicillin resistant Staphylococcus aureus in a tertiary medical centre, Nepal. Ind J Med Microbiol 8: 108-110.

9. Kumari N, Mohapatra TM and Singh YI (2008) Prevalence of Methicillin-Resistant Staphylococcus aureus (MRSA) in a
Tertiary-Care Hospital in Eastern Nepal. J Nepal Med Assoc 47: 53-56.

10. Verma S, Joshi S, Chitnis V, Hemwani N and Chitnis D (2000) Growing problem of methicillin resistant staphylococci: Indian Scenario. Indian J Med Sciences 54: 535-540.

11. Ayliffe GAJ (1997) The progressive intercontinental spread of methicillin-resistant Staphylococcus aureus. Clin Infect Dis 1: 74- 79.

12. Voss A and Doebbeling BN (1995) The worldwide prevalence of methicillin resistant Staphylococcus aureus. Int J Antimicrob Agents 5: 101- 106.

13. Voss A, Milatovic D, Wallrauch-Schwarz C, Rosdahl VT and Braveny I (1994) Methicillin-resistant Staphylococcus aureus in Europe. Eur J Clin Microbiol Infect Dis 13: 50-55.

14. Qureshi AH, Rafi S, Qureshi SM and Ali AM (2004) The current susceptibility patterns of methicillin resistant Staphylococcus aureus to conventional anti Staphylococcus antimicrobials at Rawalpindi. Pak J Med Sci 20: 361-364.

15. Tiemersma EW, Bronzwaer SL, Lyytikäinen O, Degener JE, Schrijnemakers P, Bruinsma N, Monen J, Witte W and Grundman H; European Antimicrobial Resistance Surveillance System Participants (2004) Methicillin-resistant Staphylococcus aureus in Europe, 1999-2002. Emerg Infect Dis 10: 1627-1634.

16. Goff DA and Dowzicky MJ (2007) Prevalence and regional variation in meticillin-resistant Staphylococcus aureus (MRSA) in the USA and comparative in vitro activity of tigecycline, a glycylcycline antimicrobial. J Med Microbiol 56: 1189-1193.

17. Majumder D, Bordoloi JN, Phukan AC and Mahanta J (2001) Antimicrobial susceptibility pattern among methicillin resistant Staphylococcus isolates in Assam. Indian J Med Microbiol 19: 138-140.

18. Anupurba S, Sen MR, Nath G, Sharma BM, Gulati AK and Mohapatra TM. (2003) Prevalence of methicillin resistant Staphylococcus aureus in a Tertiary care Referral Hospital in Eastern UttarPradesh. Indian J Med Microbiol 21: 49-51.

19. Rajaduraipandi K, Mani KR, Panneerselvam K, Mani M, Bhaskar M, Manikandan P (2006) Prevalence and antimicrobial susceptibility pattern of methicillin resistant Staphylococcus aureus: A multicentre study. Ind J Med Microbiol 24: 34-38.

20. Holloway K. 2000. Antimicrobial resistance: the facts. Essential Drug Monitor WHO 28 \& 29: 7-8.

21. Hart CA and Kariuki S (1998) Antimicrobial resistance in developing countries. BMJ 317: 647-650.

22. Sorlozano A, Gutiérrez J, Roman J, Liebana J and Piedrola G (2009) Activity of daptomycin against multiresistant clinical isolates of Staphylococcus aureus and Streptococcus agalactiae Microb Drug Resist 15: 125-127.

\section{Corresponding author}

Dr. Hare Krishna Tiwari

Associate Professor

Department of Microbiology

Universal College of Medical Sciences

Bhairahawa, Lumbini Zone, Nepal, POB No: 53

Phone: 00977-71-522896, Fax: 00977-71-522921

E-mail: hktiwari_2005@rediffmail.com

Conflict of Interest: No conflict of interest is declared. 